\section{A Perture}

o.

VARICOCELE IN THE FEMALE.

Givex to Gradtatis at St. Mari's Hospital, Marchester. November, 1921

$\mathrm{BY}$

Professor W. E. FO'THerGill,

HONORART SURGEON TO ST. MARY'S HOSPITAL; HONORAIY GENAECO LOGICAL SURGEON, MANCHESTEL ROYAL INFIRMAKY.

A RECENT writer remarlis that perhaps no subject in the field of gynaecology has been so thoroughly neglected as raricose veins in the female pelvis. He rightly says that there are but a few important clinical reports on the topic in the literature, and he mentions those by Winkel in 1886, by Dudley in 1889, by Miller and Kanavel in 1905. also Skenc's textbook witten in 1895. As these communi. cations are not easily available for reference I may mention that I referred to the subject in my Handbook of Diseases of Women, published in 1910, and gave a clinical lecture on it which appeared in the Clinical. Journal on March 31st, 1915. Further, a paper by J. A. Wall was printed in Surgery, Gynecology, and Obstetrics in 1916 (vol. ii, p. 61). The recent writer I have quoted is L. A. Emge, whoso paper is in Surgery, Gynecolog!l, and Obstetrics for February, 1921. As it would seem that the subject is not yet stale I propose to bring it more or less up to date in this lecture.

\section{Analomy.}

Anatomists describe five plexuses of veins in the pelvis: The vaginal, the uterine, the vesical, and the haemorrhoidal, which drain in to the inferior hypogastric vein, and, last but not least, the pampiniform plexus. 'This drains into the ovarian vein; and it must be noted that the right ovarian vein opens direct into the vcna cava, its entrance being guarded by a valve which is said to be the only one in the polvic venous systam. The left ovarian opens into the left renal vein, with nothing to prevent renous backward pressure.

'I'le vaginal, uterine, vesical, and haemorrhoidal plexuses of reins are all embedded in the subperitoneal pelvic tissue, which, besides conuective tissue of varying density coutains plenty of non-striped muscular' tissue. 'Thus these veins are well sheathed and supported. But the pampiniform plexus is made up of two masses of veins, one above and one below the ovary, and these lie simply between two 'ajers of peritoneum without any other support. The ovarian vein itself is merely covered by peritoneum and is not embedded in connective or muscular tissue.

It follows from these considerations that the veins in the bruad ligaments, and especially those of the left side, are, of all venous structures in the female body, the most liable to distension. Bunches of varicose veins in the broad ligaments are, indeed, a familiar sight to all who are in the habit of exploring the pelvis, even in the 'Trendelenburg position, through abdominal incisions.

\section{Etiology.}

It must be made perfectly clear that varicose veius in the pelvis are often seen in connexion with fibroids and other new growths, in cases of old pelvic infection and also in cases of marked retroversion. These secondary venous distensions do not coucern us at present. They have nothing to do with the case, and are managed by treating surgically the primary conditions to which they are secondary.

The varicosities in question are not secondary to any other pelvic lesion, and their causation is just the same as that of varicose veins in the legs and in the vulva. Lilie other varicose veins, those in the broad ligaments are made worse by pregnancy and by occupaticns that keep the patient standing during long hours. They are common in teachers, shop assistants, and post-office officials.

\section{Pathology.}

Congestion and oedema of the ovaries are constantly observed in these cases, and numerous small cysts are often seen after prolonged renous congestion. Overgrowth of tibrous tissue follows if the congestion is excessive. In some cases the internal secretion of the ovary would secm to be inclcased, at least for a time, for menorrhagia is a common symptom. But in other cases thore is relative amenorrhoea, which suggests sclerosis of the ovaries and atrophy of their essential tissue.

Emge says that

"with progressive distension the units of the pampiniform plexus are gradually affected until ultimately the uterine and other plexuses of the pelvis are involved also by virtue of their intimate relation through the anastomatic uterine vein."

No loubt this may be the course of events in some cases. But we see cases of extreme varicosity in the vulva or vagina, in the bladder, in the uterine sinuses, and also in the rectum, which is not extension of varicosity of the pampiniform plexus.

\section{Symptoms and Course.}

The leacling symptom is dull aching pain in the left side. low down; it is often felt on both sides, and sometimes is confined to the right side. Young girls do not complain of this pain, but its onset is often preceded by a few years of congestive dysmenorrhoea. The pre-menstrual and menstrual aching prolongs itself into the intermenstrual period, until t!e guawing pain is practically continuous except when the patient is lying down. The condition may begin to be troublesome after marriage or after par. turition, and is seldom relieved by either event. It is usual to say that the pain is made worse by constipation, and this is true in the senso that curing constipation relieves pelvic congestion. But there are some women in whom a loaded rectum is habitual, and seems to support the varicocele in some degree, for they state that they are more free from pain when the rectum is comfortably full than when it has been emptied. The natural cure of the condition ccmes, in many cases, with the menopause, for there is then a marked reduction of the pelvic blood supply, often accompanied with the deposition of much fat, which may support the veins in some degree.

It will be said that many men have varicocele without pain, and that many varicose veins in the legs do not ache. No cloubt, also, there are iunumerable women with varicocele in the broad ligaments which does not enter consciousness in the form of pain. The sensitiveness of the nervous system plays its part. The hyperaestletic woman will feel as severe aching a degree of venous distension which the ordinary woman would only describe as a feeling of weight in the pelvis or a bearing down, and the stolid woman would not feel it at all. This.is borne out by the fact that the pain often vanishes when a woman is in good health, only to return whenever she becomes run down, as, for example, after an attack of influenza.

\section{Diagnosis.}

The conclition is suspected as soon as the patient bas clescribed her symptoms and given her history. But the diagnosis is only made after excluding the conditionsnew growths, retroversion, and the results of infection-which can produce secondary varicocele or can complicate the primary form. If bimanual examination shows the pelvic organs to be normal in size, shape, consistency, and position, the leading symptom is sufficient to establish tlie diagnosis if there is no history of venereal or septic pelvic infection. I have previously written that the bunches of veins cannot be felt by the examiner ; but Emge says that this is because the patient is examined in the recumbent posture, and in this position the veins are well drained and not palpable. He states that if, during examination by the recto-vaginal touch, the patient is aslied to drop her legs and assume a sitting posture, it is often as easy to feel these veins in the female as in the male. As they fill up they form "an easily compressible and doughy tumour that is much less tender than either an inflamed or an ectopic tube." The tumour will disappear when the patient lies down again. This is quite correct. The presence of varicose veins in the legs of a patient gires
a useful hint.

The condition of varicocele in the female is generally diagnosed as ovaritis. A student who mistook varicocele in the male for orchitis would rightly be referred for a period of further study, and he should suffer the same punishment for making the same mistalie in the female patient. When the pain is confined to the right side it is possible to mistake the condition for appendicitis, and both 
may, of course, be present in the same case. When there is doubt, examination in the sitting or standing posture should clear up the point.

\section{Prognosis.}

Many women with constant pain in the sides hare healthy children one after another and have good health in other respects. The pain generally disappears at the change of life, but until that in reached there is no prospect of permanent relief in pronounced cases. "The slighter cases are amenabie to treatment in some degrec. The important factor is the patient's nerrous system. The hyperaesthetic woman, especially if she has a kind husband and srmpatlietic relatives, is likely to trausfer her patronage from one doctor to another until, after descending a scale of faith-healers and quacks, she ends up a hopeless neurasthenic, bereft of her appendix and both her ovaries. The ordinary patient, after having her discomfort explained by a wise medical adviser, will adjust her life according to his instructions, talke care of her general health, keep her bowels loose, and put up with the aching when she cannot aroid it.

\section{Treatment.}

A careful and sound prognosis is the essential element in the treatment of this condition.

Unfortunately the diagnosis of ovaritis has often led to mistalien treatment of varicocele. For the word ending in "itis" suggests inflammation. The idea of inflammation suggests the use of hot donches and glycerin plugs, which make the patient much worse. Who would blister the scrotum for varicocele and who would remove the testis? Yet square yards of blisters have been used and multitudes of ovaries have been excised for the same condition in women.

Bunches of dilated veins in the broad ligaments have often been tied and excised with temporary benefit; but the pain generally returns sooner or later, with disappoint ment as the result. It must be allowed that there is at present no local or surgical treatment available. The patient should be told to keep her bowels loose and to avoid standing, but to take plenty of active exercise-work or play. The most useful drugs in my experience are the two old-fashioned mixtures-cascara, belladonna, and strychnine; and quinine, iron, and Epsom salts. Many patients find peace by taking a small saline aperient every morning. A change of employment often worlis like a charm.

\section{ON FORECASTING.}

a Contribution to the Prognostics of Some ANOMALIES OF THE HEART AND OF THE URINE. $B Y$

W. P. S. BRANSON, C.B.E., M.D., F.R.C.P., PHYSICIAN, ROYAL FREE HOSPITAL; MIEDICAL OFFICER, SUN LIFE ASSCRANCE SOCIETY.

Forecasting is a treacherous business, especially when chronic affections are at issue. But we cannot escape it; for a patient's interest in the remoter future of his health is only second to his interest in being cured outright, and, when a cure appears to be unattainable, the problem of the future fills his field of vision.

Moreover, forecasting is potent for good or for evil, according as it is judicious or the reverse. Well men have been made sick men by ill-judged interpretations of unimportant anomalies, and sick men have been made much better by well-chosen yet honest prophecies; for "there are ways and ways," as the saying goes, of breaking bad news. I have heard it said of a well.known physician, no longer living, that a patient, consulting him for, say, Bright's disease, would leave with the conviction that Bright's disease was reserved only for the luckiest among men. Surely the height of compliment-or so it seems to me.

I will assume, then, that the first essential of a judicious prognosis is a correct interpretation of abnormal tindings. The second is, that the observer should have access in his mental library to a good supply of apposite lifehistories on which to base his forecast. But these are hard to come by. We are taught certain standards of physical health, standard interpretations of physical abuormality, and standard forecasts of disease, and spend the rest of our lives amending them in the school of experience. In this slow school we learn, among other things, two lessons which are vital to breadth of view. The first concerns the number and extent of the depar. tures from standard normality which are compatible with health. The second is that standard prognosis is but the vaguest generalization, and necessarily leaves out of account the one factor which more than all else determines the event-namely, the response of the individual to the cisease he carries. 'This factor is itself one of the utmost rariability, moulded as it is by a hundred subtle influences - heredity, temperament, success or failure, labour or ease, sobriety in living or its reverse, and who shall say what other accidents of change and chance? So we need not wonder that standard prognosis of chronic affections helps us little, nor that forecasting should be, in practice, so difficult as it is.

The third essential to judicious forecasting is optimism - strained to the furthest limits of lionesty, except in the case of the patient whose native hopefulness is such that nothing short of a good fright will make him take the precautions necessary for his safeguarding. Fortinately, if I may judge by my own crolution in this matter, ex. perience makes for optimism, on the whole. Perhaps in one's early days one's view is coloured by recent memories of many autopsies, in which were revealed the fatal endresults of diseases, but not the conditions of life and the long intervals of time which had been reguired to develop them to their lethal pitch. Certainly I am more sanguine now than I used to be.

I have said that apposite life-histories upon which to base a reasoned forecast are hard to come by. It is only the old in years and experience who have had the opportunity to collect at first hand an abundance of facts on this important subject. Even at second hand precise data are not very accessible, though a wealth of them must bo reposing in the memories of the fathers of our craft throughout the country. So I have been tempted to record in this essay a few facts which have a bearing on the prognosis of some abnormalities of the heart and of the urine, together with some tentative opinions.

Most of the facts are drawn from experience gaincd during the last sixteen years at the headquarters of a large life assurance society. It is a form of experience which gives a good insight into "the normal," for a very large majority of the people who submit themselves for examina. tion believe themselves to be well. At all events they are active and busy members of society, and represent the average of the workaday non-invalid community. Moreover, owing to the fact that the same individual is occasion. ally re-examined at intervals of years for fresh assurances, one is able sometimes to date approximately the emergence of disease and to mark its progress and duration. Lastly, the examiner in this sphere of medicine has the advantage of an instructivo custom somewhat favoured by the rejected of insurance offices, or such of them as prefer not to die punctually of their disabilities. Their custom is to revisit the scene of their sentence years after its delivery, and to flaunt their continued well-being be:ore their judge or his successor. This practice, however doubtful in taste, serves a very usefal purpose in correcting preconceptions.

Foi a good many of the facts that follow I am indebted to Dr. W. E. Risdon, until lately my senior colleague at the Sun Life Assurance Society, who has been good enough to put at my disposal instances drawn from an experienco probably unique in its extent. To him, and to thedirectors of the society for permission to make use of records, I wish to express my acknowledgements.

\section{Abnorahlities of the Hedrt.}

1. Of the Impulse.

All things considered, the position of the heart's im. pulse is wonderfully constant in adult life. If it is in the fourth space it tends to be in the nipple line, but if, being in the fifth or sixth space, it is displaced outwarass even a little, one is entitled to be suspicious. Yet occasion. ally a slight outward displacement in these spaces seems to be no more than a physical idiosyncrasy. I have met it a good many times in circumstances which offered no explanation of it. For instance-a man, aged 35, had an impulse in the nipple line in the sixth space; no increased 